\title{
RESENHA DE JANELA PARA O ÍNDICO. POESIA INCOMPLETA (1984-2019), DE ANA MAFALDA LEITE (LISBOA: ROSA DE PORCELANA, 2020)
}

Jessica Falconi

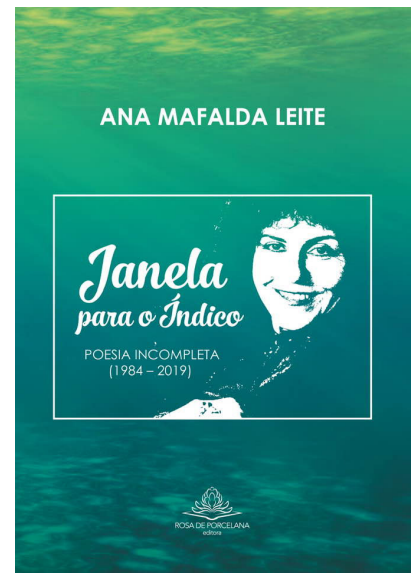

De nome em nome alguém me acena e olhando vejo que sou eu. já outro barco ana mafalda um batelão a vapor ou uma canoa a motor [...]. Ana Mafalda Leite

Janela para o Índico. Poesia Incompleta (1984-2019) é a mais recente antologia poética de Ana Mafalda Leite, publicada em Portugal pela editora cabo-verdiana/ portuguesa Rosa de Porcelana. Não podemos deixar de assinalar que o livro surgiu no panorama editorial em 2020, isto é, no ano dramaticamente marcado pela pandemia global do novo coronavírus, pelo que, a janela mencionada no 
título adquiriu um sentido ainda mais sugestivo de liberdade e abertura.

A antologia está organizada em nove secções, que correspondem aos livros anteriormente publicados pela autora, a partir dos quais foi realizada uma ampla e atenta seleção, e uma secção com dois textos inéditos ("Duas Cartas do Índico", LEITE, 2020, p. 277). Assim, esta Janela testemunha um percurso de trinta e cinco anos de escrita poética. Um percurso, este, que é paralelo a uma igualmente longa e consolidada carreira de docente e estudiosa das literaturas e dos cinemas dos cinco países africanos de língua oficial portuguesa.

Cabe realçar que a escrita poética de Ana Mafalda Leite tem vindo a ser objeto de apreciação e reconhecimento crescentes junto da crítica e do público. Os seus textos poéticos foram incluídos em diversas publicações académicas - além de antologias e revistas literárias - como por exemplo Itinerâncias (BRUGIONI et al., 2012) e Vozes femininas de África (BEGENAT-NEUSCHÄFER e QUINTALE, 2014), entre outras. Em 2015 foi-lhe atribuído o prémio Femina ${ }^{1}$ pela sua produção poética, e já em 2011 poemas seus mereceram tradução para inglês e publicação no

1 O Prémio Femina é uma iniciativa, criada em 2010, de João Micael, fundador e Presidente da Matriz Portuguesa - MPADC - Associação para o Desenvolvimento da Cultura e do Conhecimento. 
volume Stained Glass. Poetry from the Land of Mozambique, organizado por Luís Rafael Mitras. De salientar também que uma seleção de poemas, a partir de Janela para o Índico, será publicada em breve em tradução italiana, por iniciativa de Roberto Francavilla.

Assim, esta nova antologia permite-nos mergulhar nesta carreira poética e empreender uma longa travessia por fronteiras e encantações, por paisagens e geografias que são, simultaneamente, íntimas e materiais, afetivas e culturais, sendo a palavra poética desta autora um exercício incansável de mapeamento de si e do mundo.

Desde o primeiro livro, Em Sombra Acesa (1984) publicado pela primeira vez em Portugal pela editora Vega, até ao último, incluído nesta nova antologia - Outras Fronteiras: Fragmentos de Narrativas (2019) - a "poesia incompleta" de Ana Mafalda Leite apresenta-se como uma viagem em direção a variadas memórias, sabiamente entrelaçadas e reinventadas através do diálogo e da apropriação criativa e original de tradições líricas e repertórios culturais diversos. Uma poesia, diríamos, que trabalha, amplifica e até ultrapassa a dupla pertença identitária da autora - moçambicana, portuguesa - para se fazer autenticamente transnacional, convocando mares, ilhas, terras e continentes diversos. 
Nas palavras do poeta moçambicano Luís Carlos Patraquim, trata-se de uma poética marcada pelo cosmopolitismo (PATRAQUIM, 2000, s.p.) e, acrescente-se, uma poética que assume, desde o princípio da sua elaboração, o espaço liminar da fronteira como lugar de enunciação e, também, de indagação dos enigmas que habitam tanto as esferas mais íntimas do eu, quanto os imaginários coletivos.

Para empreendermos esta viagem, serve-nos um poema de Em Sombra Acesa que pode ser considerado, de pleno direito, uma ars poetica inaugural, como sugere o título: "A origem deste gesto", onde se indaga a relação entre as coisas e as palavras: "as coisas ressentidas são palavras recriadas intensas e longas [...]." e onde "tudo se passa como se da água branca crescesse um/ murmúrio tangível. nem grito nem voz. ruído menor à natureza/ quieto e circunscrito" (LEITE, 2020, p. 29). Neste e noutros poemas desta secção inicial de Janela para o Índico, anunciam-se alguns dos traços estilísticos estruturantes da escrita poética da autora. Entre eles, saliente-se a busca da musicalidade, procurada e conseguida através de recursos de vária natureza - semânticos, rítmicos e, inclusive, gráficos. A nível semântico, tal busca é trabalhada tanto pela relação que a poesia estabelece explicitamente com a música, quanto a partir da incorporação paciente 
e constante das múltiplas sonoridades e vocalidades do mundo humano e não-humano.

Outros traços relevantes que emergem desde os primeiros livros da autora são a autorreflexividade de cariz metapoético - vimos a ars poética inaugural - e sobretudo, como realçou Paula Morão no prefácio à edição original de Em Sombra Acesa, a mistura de tom lírico e narrativo, como já testemunham alguns poemas desta secção inicial da antologia: "As mãos das árvores" (p. 28); "Contas e missangas" (p. 30), entre outros.

De salientar também que às vertentes lírica e narrativa se junta a experimentação do desdobramento de cariz dramático, que se tem vindo a consolidar como outra peculiaridade do universo poético da autora, o que revela o seu desejo e a sua capacidade de explorar os muitos modos de ser da poesia. Através da modalidade dramática, o universo poético de Ana Mafalda Leite mostra-se habitado por múltiplas vozes e falas, tratando-se de um universo complexo, polifónico e povoado de instâncias, de que a labor poética se faz receptáculo, como se lê em vários poemas de Canções de Alba (1989), que corresponde à segunda secção da antologia: "Fala do poeta" (p. 37); "Primeira fala do marinheiro" (p. 38); "Segunda fala do marinheiro" (p. 39). 
E emergem também, a partir desta secção, a inquietação e o questionamento da busca de origens e princípios simbolizados pela alba do título - bem como uma apetência por círculos e espirais, em lugar de linhas retas, como formas privilegiadas para pensar, (re)organizar e representar, em geometrias arredondadas, a relação com o corpo, o espaço, o tempo:

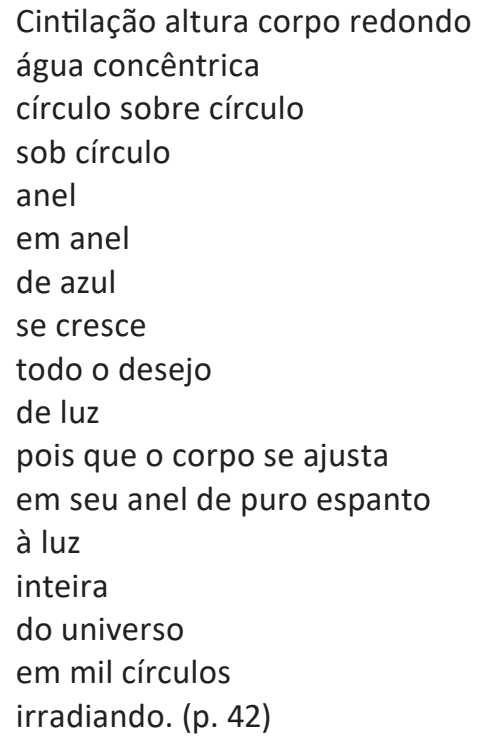

Como realçou Patraquim, já desde os poemas compostos no diálogo intersemiótico com a pintura de Roberto Chichorro - reunidos na secção Mariscando luas (p. 45) - e os textos do terceiro livro da autora, Rosas da China (1999), Ana Mafalda Leite vai inscrevendo a sua proposta poética 
"em direcção a uma mestiçagem integrando, num erotismo iniciático, tanto a pertença vivencial afro-europeia quanto um mais amplo quadro de referências poético-literária" (Patraquim, 2000, s.p.). Dentre tais referências, destacam nitidamente, em Rosas da China, as citações de Fernando Pessoa - "Livro do Desassossego" - e sobretudo de Florbela Espanca - "Charneca em flor", "Livro de mágoas", "Livro de Soror Saudade" (LEITE, 2020, p. 71-82). Urbano Tavares Rodrigues captou neste livro "a tradição lírica medieval, as cantigas de amigo, [...] Bernardim [Ribeiro], [...] o Camões lírico. E não há nisso contradição. É o legítimo e natural diálogo das vozes próprias e alheias, as que ficaram connosco, que vibram na nossa voz, são corpo do nosso corpo" (RODRIGUES, 2002, p. 444). Estes ecos e referências dão-se em combinação com epígrafes de poetas moçambicanos - Gulamo Khan - e com a longa tradição de variações sobre a rosa de Gertrude Stein - a rose is a rose is a rose... - ou ainda possíveis reescritas do "verde que te quiero verde" de Federico García Lorca: "rosa te quer rosa" (LEITE, 2020, p.63), entre outros.

Diríamos, então, que a instância de mestiçagem poética assinalada por Patraquim assume uma dimensão de moçambicanização mais declarada com o livro Passaporte 
do Coração, publicado pela primeira vez em 2002 pela editora portuguesa Quetzal. Como bem demostra a seleção de poemas deste livro incluída em Janela para o Índico, é em Passaporte que se dá, de modo inequívoco, a inscrição da poesia da autora na tradição poética moçambicana. Acrescente-se, mais especificamente, que se trata de uma inscrição naquela que veio a ser definida de "vertente índica" da tradição poética moçambicana, isto é, uma vertente que convoca o Oceano Índico como matriz cultural plural e espaço de elaboração estética (LEITE, 2003). Tal vertente, inaugurada concretamente pela poesia de Alberto de Lacerda, Orlando Mendes, Virgílio de Lemos, Rui Knopfli - e cultivada até à contemporaneidade por Luís Carlos Patraquim, Eduardo White, Armando Artur, Sangare Okapi - teve funções diferentes ao longo do tempo, entre as quais interessa-nos destacar a importância da abertura do cânone da moçambicanidade literária e cultural para a diversidade caraterizadora do Oceano Índico (FALCONI, 2013), entendido, com as palavras de Isabel Hofmeyr, como um "mar problematizador" (HOFMEYR, 2019, p. 101).

A inscrição de Ana Mafalda Leite nesta vertente índica dá-se, nitidamente, nos poemas de Passaporte, pela opção por evocar a paisagem física e, sobretudo, cultural de um 
lugar matricial do imaginário literário moçambicano, isto é, a Ilha de Moçambique, cidade-ilha do Oceano Índico. Como numa viagem iniciática e secreta, o sujeito poético de Passaporte constrói uma densa rede de referências à produção poética moçambicana, convocando Rui Knopfli, Glória de Sant'Anna, Armando Artur, Luís Carlos Patraquim, isto é, vozes poéticas moçambicanas que, como já referido, fundaram e alimentaram o imaginário cultural da llha de Moçambique e, mais em geral, do Oceano Índico quer como espaço concreto de trocas culturais, quer como metáfora de matrizes identitárias que extravasam as fronteiras dos estados-nações.

Este oceano, que se configura como uma poderosa "geografia transnacional do imaginário", é evocado pela palavra poética da autora através da metaforização da sua cultura material. Trata-se de um exercício de registo sensorial e cultural que devolve a espessura de identidades e memórias, entrelaçadas ou justapostas, no pequeno espaço da Ilha, que funciona como sinédoque do mosaico cultural do Oceano Índico. Veja-se, por exemplo, o poema intitulado "O ourives", que é, a nosso ver, um dos poemas mais representativos deste processo de metaforização da cultura material levado a cabo pela autora de Passaporte 
do coração. De facto, no poema, os saberes artesanais e as matérias-primas da joalharia local - a prata, o ouro, o marfim, etc. - são associados à ação do tempo e do mar sobre uma matéria-corpo que percebemos ser a própria ilha:

Mão atenta marchetando a prata moeda cremada xerafim antigo desfeito em arabesco impreciso que jóia tu almejas para os dedos que sonham ó ourives do tempo? [...] meticulosas, precisas, tuas mãos embutem uma fresta de júbilo nas curvas espirais desses brincos intermináveis estendidos sobre o mar à superfície lembram algas iridescentes candelabros de luz oficina de um corpo flutuante levantado por sobre a água. (LEITE, 2020, p. 96)

Veja-se, ainda, no poema intitulado "Esteira sobre o mar", a mesma lógica de materialização da ilha-corpo através da evocação de outros elementos distintivos das culturas do Índico - as especiarias, os têxteis, etc. - e de referências à história milenar dos trânsitos e tráficos identitários, travados entre a ilha e o mar, entre a costa leste de África e as outras margens do Oceano Índico:

Te envolvem o corpo brancos panos de linho e algodão mercadores baneanes canarins mouros de surrate e cambaia artífices e gentios 
bailadeiras

bailam

manilhas no pescoço pulsos e pés

vivos de seda lavrados a ouro

largas túnicas esvoaçantes

ademanes voluptuosos

moedas tilintantes escravaria marfim e oiro por entre alvos turbantes e cofiós masca-se folha de betel com noz de cola o aroma do caril de coco com bambolim apimenta as línguas em marata hurdu ou macua árabe swahili português. (LEITE, 2020,105)

Conjugando e explorando a apreensão do material e o imaterial, a deambulação deste sujeito poético pelo universo insular e índico, em linha com a tradição da poesia moçambicana, regista as diferentes presenças culturais e religiosas. Em diálogo explícito com os poemas de Rui Knopfli reunidos em A Ilha de Próspero (1972), que também captavam a babel linguística, cultural e religiosa da llha de Moçambique, o poema da autora intitulado "Ouvindo os mantras da Ilha" mergulha na sonoridade espiritual e natural deste lugar:

Meca medina mesquita mihrab minar capitel barroco igreja lupanar arcos ornados com cordames e amarras de diu chegam os fumos incensados vagueiam pelas casas de macúti os espíritos assim misturados [...] nesta terra que é ilha e porto sagrado 
de chegada e partida

se encontram

os templos do mundo

entrançados

o feiticeiro e o maulane evocam os favores dos antepassados o

hindu acende o altar em fogo lento o padre desfia versículos de areia. (p. 107)

Podemos afirmar que em Passaporte, como demostram os poemas citados, e outros, projetam-se uma llha de Moçambique e um Oceano Índico enquanto arquivos de histórias e memórias coletivas e individuais, em que a matéria aquática é indissociável da "substância" histórica, sendo que o Índico emerge "como continuum natural-cultural de conexões" (MUECKE, 2010, p. 39). Este aspeto fundamenta a nossa hipótese de que Passaporte constitui um livro-viragem no percurso poético de Ana Mafalda Leite, em que se opera uma mozambicanização das referências culturais também no que se refere à imagem feminina. De facto, a "recorrente imagem da menina-noiva-princesa-amante-à-espera" (PATRAQUIM, 2000, s.p.) que emergia nos poemas de Rosas da China, é recodificada, em Passaporte, pela imagem da "penélope de $\mathrm{m}^{\prime}$ siro² $^{2}$ enfeitada", isto é, a figura por antonomásia, na cultura ocidental, do feminino associado à

2 O m'siro é uma massa branca obtida da mistura de água e fragmentos de ramos de aárvore friccionados numa pedra. Tem funções cosméticas e rituais muito específicas na zona norte do litoral moçambicano. 
espera, mas aqui culturalmente moçambicanizada, como se lê no poema "Navega-me a alma uma ilha":

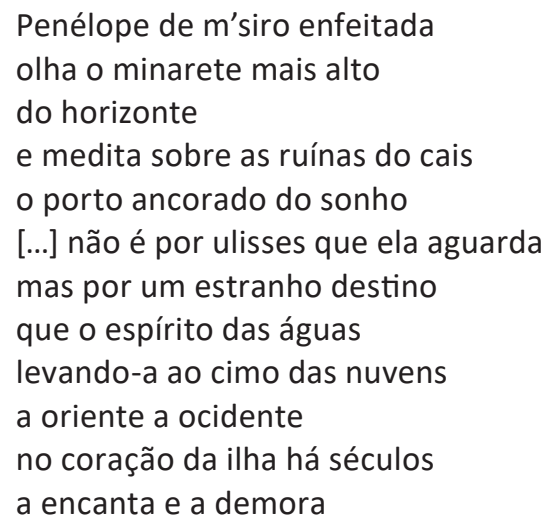

Repare-se, ainda, na possibilidade de lermos este poema como reformulação, em perspetiva feminina, do poema em prosa de autoria de Luís Carlos Patraquim dedicado à Ilha de Moçambique, "Os Barcos Elementares". Leia-se, em diálogo com o anterior, o seguinte excerto de Patraquim que também incide na apropriação de referências culturais:

De oriente a oriente flagelaste o interior da terra. De Calicut e Lisboa a lança que o vento lascivo trilhou em nocturnos, espamódicos duelos e a dúvida retraduzindo-se agora entre campanário e minarete. Muezzin alcandorado, inconquistável. Porque ao princípio era o mar e a ilha. Sinbas e Ulisses. Xerazzade e Penélope. Nomes sobre nomes. Língua de línguas em Macua matriciadas. (PATRAQUIM, 1992, p.42) 
Uma leitura atenta de Passaporte não poderá deixar de registrar que ao movimento cultural e geograficamente territorializado pela paisagem da llha de Moçambique se conjuga outro movimento, um contraponto inquieto e íntimo que realça o desenraizamento e a resistência à tirania dos mapas, como se pode ler nos poemas "Livre trânsito" e "Passaporte do coração": "[...] falta-mea/ vontade dos mapas a certeza da escolha das geografias o território/ das pátrias" (LEITE, 2020, p. 103); "coração sem pátria sem continente sem mapa/ coração alheio e estrangeiro" (p. 111).

Este movimento dúplice, registrado em Passaporte - de um lado o mapeamento e a procura das matrizes culturais; do outro um "livre trânsito" declaradamente "anti-mapas" - perpassa também os livros posteriores da autora, tal como a referência ao Índico, como o título da antologia afirma sem deixar espaço a dúvidas. A nosso ver, tratase de um movimento de avanços e recuos, suscetível de ser identificado com o movimento ondulatório das ondas marinhas e a sua relação eterna e rítmica com a terra. Como as ondas do mar, a poesia de Ana Mafalda Leite lambe as terras e funde-se com as terras, logo recuando e renovandose a cada instante. E tal como acontece em relação ao Oceano Índico e às suas fronteiras controversas ${ }^{3}$, o sujeito

3 Referimo-nos aqui às dificuldades e aos debates registrados pela historiografia sobre a 
poético questiona as fronteiras dos mapas, em demanda constante de reformulação. Assim, o que sugerimos é que a dinâmica própria do Oceano Índico, enquanto substância natural/cultural, não é apenas um recurso temático para a autora, mas um dispositivo ubíquo e estruturante do ritmo global da sua produção poética.

Novas travessias e deslocamentos "moçambicanizantes" procuram abertamente genealogias poéticas e afetivas e uma possível e múltipla morada para o rosto e o nome próprio que emergem no Livro das Encantações (2005). Este nome próprio - ana mafalda, em letra minúscula - juntamente com o rosto e o corpo vão sendo enunciados de acordo com o dúplice movimento já registrado, como revelam os poemas "Tenho o nome de um barco", "Fronteira líquida" e “Do outro lado, a Sul, Trópico de Capricórnio". No primeiro, empreende-se uma (des)localização - biográfica, histórica, cultural - assumindo-se, no nome, a ligação entre mares e hemisférios, entre nação e império:

Ana Mafalda um barco do império em travessia entre dois oceanos me fez nascer. foi esse o nome que me deram ao levar-me transplantada de um hemisfério para o outro.

nasci entre fronteiras líquidas entre ondas

definição dos limites objetivos do Oceano Índico. 
inventei um berço.

foi um nome que me nasceu, foi um barco, um deslizar de marés no final da década de cinquenta. (p. 154)

Em "Fronteira líquida" a duplicidade é assumida como traço do ser, localizado no próprio corpo - a palma da mão - sendo que o rosto permanece múltiplo e lacunar: “assim o meu rosto está na sombra desde sempre/ até que o preciso número de luas encontre a/ geometria exata para o iluminar" (p. 143). Como realça Joana Passos, o poema "Fronteira líquida" é um exemplo significativo de uma sensibilidade "in-between" que desestabiliza fronteiras fixas e certezas identitárias, abrindo para a ubiquidade de vidas múltiplas (PASSOS, 2008, p. 146). No terceiro poema, reafirma-se o apelo do "livre trânsito de Passaporte: "na verdade não escolhi o mapa e detesto que os lugares me prendam ao chão. A minha natureza é andarilha e precisa de calor para crescer" (LEITE, 2020, p. 152). Assim, o sujeito poético desloca-se do centro para as margens, na distância apreendida por um olhar que se quer geodésico: "desço os olhos para o trópico de Capricórnio, abro as cortinas da imaginação e o sul desenha-se por entre dedos açafrânicos (p.155).

Fixadas as genealogias poéticas no poema-carta "Naturalidade (uma carta a Rui Knopfli)" (p.141-142) em que 
se reclama a única naturalidade possível - a da poesia anunciam-se as "paisagens estranhas do coração" que são exploradas como autênticos territórios de desnorteamento em O Amor essa forma de desconhecimento (2010), publicado pela primeira vez em Moçambique pela editora Alcance. Trata-se de um livro que traça um caminho desviante e paralelo no trabalho de reflexão poética de Ana Mafalda Leite sobre o amor, focando-o enquanto experiência radical tanto da identidade quanto da alteridade. Como observou Silviano Santiago no prefácio à primeira edição, "dizer que o amor é uma forma de desconhecimento ... é atirá-lo para o limiar do não-consensual e do não-sabido pelo leitor" (SANTIAGO, 2010, p. 5). De facto o amor e a relação amorosa são representados recorrendo às metáforas geográficas e espaciais - elementos distintivos da poética da autora: "Um país desconhecido", onde o sujeito poético experimenta uma irredutivel "Estrangeira condição", porque:

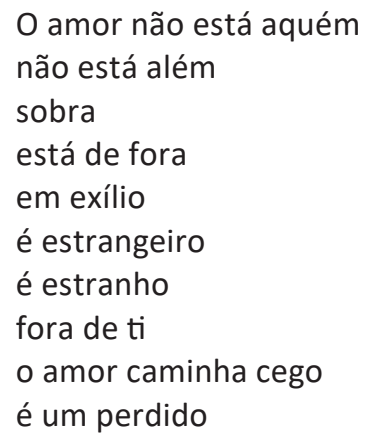


não sabe caminhos nem mapas o amor é uma forma de desconhecimento. (p. 179)

Por outro lado, como realça Vera Maquea em sua interpretação deste livro da autora, definir o amor como uma forma e não um conteúdo, "desloca totalmente sua condição de tema nesse livro. [...] Portanto, é sobre o sujeito e não sobre a coisa (ou o sentimento) que repousa o problema" (MAQUEA, 2020, p. 5). Concordamos com esta interpretação que realça a dimensão essencialmente autorreflexiva e identitária desta etapa do caminho poético da autora. É a partir desta "estrangeira condição" que o amor se faz metáfora do questionamento do conhecimento do outro enquanto aspiração, prática, exercício de poder. Questionamento das suas categorias - o tempo e o espaço; das suas estruturas e linguagens: "é pelo infinitivo presente que se chega ao verbo amar/ [...] amar/ devagar reflicto no verbo e no tempo e não sei em que tempo me conjugar será que o espirito se anima de um advérbio sempre?" (LEITE, 2020, p. 205). Leia-se também em "Coração adiado":

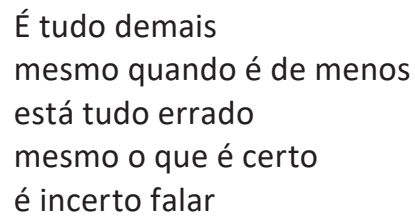


atirar palavras ao ar como um mágico solta pássaros alados para de imediato os prender em agarrados gestos e lhes roubar as asas não sabes que o voo é oficina de asas? (p. 182)

Surge aqui, como noutros poemas, a evocação à "ciência e engenharia de ser ave", de Eduardo White, tão presente nesta antologia desde o seu título, que reescreve a sua Janela para oriente.

O sujeito poético de Amor sugere que o amor enquanto relação identidade/alteridade impõe outra ciência, outra engenharia, outra linguagem, para se atribuir sentido à escuridão projetada por estes poemas. A busca, neste caso, é de possíveis coordenadas - íntimas, culturais - que harmonizem o que se conhece desconhecendo-se: "não há memória que recorde/ e não tem nenhuma língua porque as tem a todas".

Será então o desconhecimento a única possível "epistemologia" do amor? Será o sul o lugar de enunciação desta epistemologia? Será o desconhecimento uma renovada deslocação do centro para as "margens", para um "hemisfério sul" (p. 204) ou para "a margem invisível do mundo" (p. 202), tão recorrente no universo poético de Ana Mafalda Leite? Será esta deslocação um reflexo não apenas de sua biografia e dupla pertença, de seu nascer e escrever 
entre fronteiras líquidas, mas também do seu compromisso ético e crítico com conhecimentos e cosmovisões outras? Julgamos que sim e que a mais recente etapa do seu itinerário poético, apresentada na penúltima secção da antologia Outras fronteiras, fragmentos de narrativas - vem confirmar uma visão dos saberes que podemos definir de "ecológica", convocando, aqui, o conceito de "ecologia de saberes" formulado por Boaventura Sousa Santos: “É uma ecologia, porque se baseia no reconhecimento da pluralidade de conhecimentos heterogéneos (sendo um deles a ciência moderna) e em interações sustentáveis e dinâmicas entre eles sem comprometer a sua autonomia" (SANTOS, 2009, p.44-45). Assim, para o sociólogo português, a ecologia de saberes pretende questionar a hegemonia absoluta do conhecimento científico ocidental, fundando-se numa pluralidade epistemológica que reconhece a importância de outros conhecimentos: "conhecimentos populares, leigos, plebeus, ou indígenas" (p. 25).

Tal perspetiva ecológica alicerça, em nossa opinião, a recente aventura poético-epistemólogica empreendida em Outras Fronteiras, dividido em quatro partes: "Como se a manhã do tempo despertasse"; "Poemas de Moatize"; "Outras Fronteiras: Fragmentos de Narrativas"; "O Índico em Marrakesh". Atente-se nos títulos de alguns dos poemas 
para se detectar a vertente epistemológica que julgamos identificar nesta secção: "Tratado das cores em Moatize"; "Teoria das cores ou o primeiro olhar"; "Corpos lúcidos e opacos, ciências \& ouvindo um soneto" (sublinhados nossos); atente-se, também, nestes versos do longo poema que dá o título ao livro, "Outras fronteiras: fragmentos de narrativas": “[...] raiz quadrada/ noves fora sempre indago a matemática sem resultado será que é indígena?/ será que é alienígena? será que é?" (LEITE, 2020, p. 244).

Esta incursão de cariz epistemológico conjuga-se à mobilização da memória pessoal, originando uma espécie de "Bildungsgedicht", isto é, poesia de formação que repercorre etapas crucias de construção de si e da relação com o mundo. Acompanhamos, assim, um processo que é simultaneamente íntimo e intelectual, de revisitação de aprendizagens, interrogadas a partir do filtro da memória e reformuladas através do saber da poesia. Veja-se, nesta perspetiva, o poema "Tratado das cores em Moatize", no qual se refere Newton e as suas teorias sobre a refração da luz para se recomporem memórias e paisagens da infância evocadas pela sua materialidade e apontadas como matriz da imaginação poética:

Com o caderno nos joelho leio: newton escreveu Que a luz consiste em 
pequeninas partes de matéria que saem de um corpo lúcido em todas as direç̧ões

[...] carvão intenso nas estradas nas minas por dentro da terra por isso o vermelho sangra em azul e a cor verde resplandece em amarelo Moatize: as cores primeiras! (LEITE, 2020, p. 227)

Veja-se, ainda, o aprendizado das cores - naturais, humanas, culturais - que o sujeito poético foi fazendo com a poesia moçambicana, retraduzido como interrogação ontológica sobre as origens do universo e da humanidade:

O Virgílio dizia negra azul ${ }^{4}$ eu digo somos todos azuis

Mas interessa saber a cor do universo?

(Coisa estranha aqui tão evidente)

[...] no princípio fomos azuis?

agora ainda verdes antes do rubro apocalíptico em extinção passional. (convém não esquecer). (p. 229)

São indagações poéticas sobre a luz, as cores, a matéria e sobre a história e a geografia do continente africano, em que se inscreve o exercício de reescrita do diário da viagem a Moçambique do astrónomo e viajante paulistano Lacerda e Almeida. Aos saberes oficiais, pilares do pensamento

4 Refere-se ao livro Negra azul de Virgílio de Lemos, 1999. 
científico, objetivados nas parafernálias do conhecimento (bússolas, telescópios, etc.), justapõem-se nesta secção da antologia outros saberes, outras "ciências e engenharias" constituídas pelos repertórios culturais africanos ("Poemas do Nyau, a grande dança"), que estruturam intimamente o imaginário e a visão do mundo aqui veiculada. Como realçou Gustavo Henrique Rückert a propósito de Outras fronteiras "o deslocamento assume um sentido inverso à literatura de viagem colonial: da "colônia" aos "outros mundos". É no solo africano que a terra acaba e o mar começa" (RÜCKERT, $2019,142)$. Por outro lado, os repertórios culturais africanos moldam também esta outra ciência, esta outra forma de saber e apreender o mundo que é a rememoração da infância, através do mapeamento poético do seu lugar matricial representado pela vila de Moatize, com a sua materialidade de carvão, as suas minas inesgotáveis de lembranças.

Fecham a antologia dois textos inéditos que (re)convocam o Índico como lugar de enunciação: "Duas cartas do Índico". A primeira carta-poema, "As ilhas", aponta para a geografia insular deste oceano, convocando as Maurícias e uma das suas vozes literárias mais destacadas, a da escritora Ananda Devi. Assim, a carta parece apontar para os contornos de uma estética transnacional do Oceano Índico, sugerida 
como sendo "um pensamento de mar", "um extenso abraço de coral", aludindo também ao conceito de "identidade coral" teorizado pelo poeta mauriciano Khal Torabully para equacionar as identidades culturais surgidas das histórias ocêanicas de diásporas e deslocações.

A segunda carta tem como subtítulo "A casa do meu pai", o que evoca de imediato a incontornável reflexão sobre o continente africano de Kwame Anthony Appiah (In my father house). Como anunciado pelo título, a carta é uma longa declinação da morada do eu e da poesia, uma morada que é simultaneamente múltipla e singular, marcada pelas relações constitutivas do sujeito poético com o universo cultural e social moçambicano, homenageando-se outra sua cantora, Noémia de Sousa, e seu "poema da infância distante".

Assim, ao longo desta travessia pela poesia incompleta de Ana Mafalda Leite, julgamos ter descoberto um sujeito poético que se procura e se reconhece no questionamento e na fronteira: "Saberei porventura os lugares de onde fala esta voz? Os enigmáticos espelhos de onde se olha?" (Outras Fronteiras, 2017). Outras viagens empreende este sujeito poético em devir constante, que se quer "assim repartida em minhas pedrinhas espalhada em rios de terra e/ minérios quentes" (p. 243). Outras fronteiras e fragmentos de 
narrativas que é possível recompor e contar a partir de uma dúplice materialidade: a do coral, no oceano Índico, e a do carvão, nas terras de Moatize, ali, "nas muitas casas do meu pai" onde "se abriu a janela para o índico país"(p. 281).

\section{REFERÊNCIAS}

BEGENAT-NEUSCHÄFER, Anne; QUINTALE, Flavio (Orgs.). Vozes femininas de África. Oxford: Peter Lang, 2014.

BRUGIONI, Elena; PASSOS, Joana; SARABANDO, Andreia; SILVA, MarieManuelle (Orgs.). Itinerâncias. Percursos e Representações da Póscolonialidade. Famalicão: Húmus, 2012.

FALCONI, Jessica. Para fazer um mar. Literatura moçambicana e Oceano Índico. Diacrítica, 27, p. 77-92, 2013.

HOFMEYR, Isabel. Um mar problematizador. O Oceano Índico como método. In: LEITE, Ana Mafalda; BRUGIONI, Elena; FALCONI, Jessica (Orgs.). Estudos sobre o Oceano Índico. Antologia de textos teóricos. Lisboa: Colibri, p. 101-116, 2019.

LEITE, Ana Mafalda. Literaturas africanas e formulações pós-coloniais. Lisboa: Colibri, 2003.

MAQUEA, Vera. Notas do contemporâneo na poesia de Ana Mafalda Leite. Caletroscópio, v. 8, n. 1, janeiro-junho, p. 106-123, 2020.

MUECKE, Stephen. Fabulation Flying Carpets and Artful Politics in the Indian Ocean. In: MOORTY, Shanti; JAMAL, Ashraf (Orgs.). Indian Ocean Studies. Cultural, Social and Political Perspectives. New York: Routledge, p. 32-44, 2010.

PASSOS, Joana. Talk back and think beyond: the reception of African literatures in Portugal and the self-definition of postcolonial nations through literature. In: LOPEZ, Marta Sofia (Org.). Afroeurope@ns. Cultures and Identities. Newcastle: Cambridge Scholar Publishing, p. 65$78,2008$. 
PATRAQUIM, Luís Carlos. Enumeração declinada da rosa, Público, 2000. Disponível em: https://www.publico.pt/2000/02/26/iornal/enumeracaodeclinada-da-rosa-140577. Acesso em: 24 de jun. de 2021.

PATRAQUIM, Luís Carlos. Vinte e tal novas formulações e uma elegia carnívora, Linda-a-Velha, ALAC, 1992.

RODRIGUES, Urbano Tavares. Recensão crítica a Rosas da China de Ana Mafalda Leite. Colóquio-Letras, n. 161-162, julho, p. 444-445, 2002.

RÜCKERT, Gustavo Henrique. As geografias do acaso cartografadas em Outras fronteiras, de Ana Mafalda Leite. Conexão Letras, Porto Alegre, v. 14, n. 21, p. 141-144, janeiro-junho, 2019.

SANTIAGO, Silviano. O verbo amar se anima da minha eternidade. In: LEITE, Ana Mafalda. O amor essa forma de desconhecimento. Maputo: Alcance Editores, 2010.

SANTOS, Boaventura de Sousa. Para além do pensamento abissal: das linhas globais a uma ecologia de saberes. In: SANTOS, Boaventura Sousa; MENESES, Maria Paula (Orgs.). Epistemologias do Sul. Lisboa: Almedina, p. 23-71, 2009.

Jessica Falconi

Investigadora auxiliar do Centro de Estudos sobre África e Desenvolvimento (CesA) e membro integrado do Centro de Investigação em Ciências Sociais e Gestão (CSG) do Instituto Superior de Economia e Gestão (ISEG) da Universidade de Lisboa (UL).

Pós-Doutora pelo Centro de Estudos Sociais da Universidade de Coimbra (UC) e pelo Centro de Estudos sobre África e Desenvolvimento (CesA) da Universidade de Lisboa (UL); Doutora em Estudos Ibéricos pela Universidade de Nápoles.

https://www.cienciavitae.pt//141B-8BB8-E5D5

https://orcid.org/0000-0001-7496-8274

iessica-77@libero.it 